\title{
1 Design and optimization by Response Surface of a FAO grade-handicraft prototype for yucca starch extraction
}

\section{Arsenio José Rodríguez Salazar}

5 Laboratorio de Productos Naturales, Área de Agricultura y Soberanía Agroalimentaria, Fundación Instituto de Estudios

6 Avanzados - IDEA, Caracas (Venezuela).

7 Corresponding author: arseniorod@pm.me

8 ORCID ID: 0000-0003-3577-1537

10 ABSTRACT

11 Yucca starch (Manihot esculenta Crantz) plays several important roles in agroecological agriculture

12 in the tropics. It is an inexpensive source of carbohydrates of high nutritional quality and easily

13 accessible, if preserved and stored. The process of starch artisanal extraction is carried out in Latin

14 America in a rudimentary and impractical way, with water and raw material wasted, which

15 generates losses and ecological problems. This study shows how a prototype of a technological

16 process (Matilda v1.0) for the artisan extraction of yucca starch with FAO grade quality was

17 designed, built, and optimized. The optimization was performed using the response surface

18 methodology, and the experimental design is a Box-Wilson $2^{3}$ full factorial central composite,

19 uniformly rotated and orthogonally blocked per day. Around $60 \mathrm{~kg}$ of starch for $200 \mathrm{~kg}$ yucca on a

20 working day was obtained. The estimated starch yield was $31.83 \%$, within a confidence interval of

$21(30.24-32.97) \%$ and a prediction interval of (27.98-35.23)\%. This yield was higher than that

22 reported for conventional artisanal extraction. Water use was about $0.3 \mathrm{~L} \mathrm{~kg}^{-1}$ yucca, significantly

23 lower than in artisanal productions. The process developed would generate a lower impact on the 
24 environment and would allow small agricultural producers to empower themselves with sustainable

25 technologies.

27 Key words: flour substitute, starch flour, composite central design, sustainable technology.

\section{Introduction}

30 Yucca (Manihot esculenta Crantz) is a plant whose roots provide food and maintenance to more

31 than 600 million people worldwide. This plant tolerates seasonal droughts and poor soils and has

32 the incomparable ability to recover after stems and leaves have been affected by pests and diseases

33 (Domínguez et al., 1983; Álvarez et al., 2002; Parmar et al., 2017). Yucca is a very accessible crop

34 in Venezuela where it is mainly used for fresh consumption and the production of flour and starch.

35 It contains more starch by dry weight than any other food crop. This makes yucca flour, the ideal

36 substitute of foreign products, such as wheat flour (Alarcón \& Dufour, 2012). These imported flours

37 represent important currency expenditure for both the public and private sectors in our country and

38 the rest of the world (Cartay, 2004; Zambrano \& Sosa, 2018; Oliveira et al., 2019).

39 In different areas of industry, the gelling agents used for the preparation of crop media are costly

40 and difficult to obtain, which delays the process of research and production of bio-inputs developed

41 in Venezuela. This led us to search for a viable and low-cost alternative in the evaluation of starch

42 as a gelling agent (Maliro \& Lameck, 2004; Romay et al., 2006).

43 Yucca starch is a natural polymer composed of 20-30\% amylose (linear polysaccharide) and 70-

$4480 \%$ amylopectin (branched polysaccharide). This particular combination and the nature of the

45 starch components result in native rheological properties (viscosity, viscoelasticity, dispersion

46 stability, etc.) which might suggest the use of yucca starch as a gelling agent. Although the 
47 extraction of yucca starch is achieved with simple and manual technologies, these are very

48 laborious, using excessive water consumption and very low yield (Zhu \& Xie, 2018; Ngnassi et al., 49 2019).

50 In this research, a total of 73 bibliographic references was evaluated on the design of prototypes for

51 the extraction of starch of plant roots, Musaceae, tubers, legumes, cereals, and other sources, both

52 artisan and semi-industrial. Those prototypes were chosen when they met two or more of the

53 following design criteria: low water use, manual traction, made with low-cost materials, compliant

54 with the starch extraction process proposed by FAO, safe to the operator at the time of its use, and

55 easy operate and maintain). Producers and artisans from different localities of Venezuela involved

56 in artisanal starch extraction were consulted (Acosta, 2005; Saranraj et al., 2019). A summary was

57 made including the most important ideas collected from the previous process. Then, the different

58 works and experiences were considered, discussing the design parameters that should be met by the

59 FAO grade technological process. With FAO grade, we want to point out that the quality of the

60 starch obtained meets the standards of the Codex Alimentarius (FAO \&WHO, 1995). After

61 exhaustive reviews, preliminary designs of machines in freehand sketches were carried out; these

62 drafts met the criteria of the technological process of yucca starch extraction (Acosta, 2005; Bello-

63 Pérez et al., 2006; Shittu et al., 2016)

64

65 This study shows the design, construction, and optimization of a technological process (Matilda

$66 \mathrm{v1.0)}$ that allowed for the production of FAO grade yucca starch at low cost. As a result, not only a

67 substantial saving of water is achieved, but also the performance above the average artisanship and 68 easy operation and maintenance.

69 
71 Design, technical memory, and construction of the technological system for the extraction of

72 yucca starch from FAO (Matilda v1.0)

73 For the design of the technical proposal, the project management methodology was used (Young,

74 2007). The technical project described:

75 A) The technical problem: the artisanal extraction process of starch is carried out in a rudimentary

76 and impractical way, where the use of resources such as water and raw materials are not very

77 efficient, generating economic losses. This represents an ecological problem due to the abundance

78 of waste produced;

79 B) The prior technical proposal: after the exhaustive described review, several sketches or 80 preliminary designs that were framed within the pre-established criteria were specified. We

81 discarded those that did not comply with the technical and economic feasibility. Prototypes were

82 built from the definitive preliminary design for their proof of concept. Subsequently, the final

83 preliminary design was chosen, and the construction plans were created using FreeCAD v0.15

84 software (FreeCAD, 2015);

85 C) The general report: consisted of a final technical proposal which set out the entire essential

86 factors that the technical project must solve. A preliminary draft was made, accompanied by

87 drawings (sketches), which included all the suggested indications. A descriptive report was prepared

88 including the final solution chosen, materials to be used, the process followed for the construction

89 of the prototype, approximate cost and handling of the prototype. Finally, the CAD isometric plans

90 of the final solution were made; 
91 D) General plan: a general plan was designed that showed the general dimensions of the technical

92 system chosen as a solution. This was done through bounded views (raised, planted, profile), which

93 allowed us to obtain a simple and clear drawing as much as possible.

94 Also, a general plan was elaborated that showed the different pieces that made up the machine and

95 the relative location of each of them. A view of the whole machine was made and using tags to

96 identify its parts. For both, the set and each of the pieces that made up the machine, a diagram was

97 made where the technical characteristics of each piece and their manufacture were reported:

98 - Measurements of each piece in mm (information obtained from the general drawing);

99 - Material with which the piece was to be manufactured (information extracted from the previous

100 definitive design);

101 Number of pieces to be made (information extracted from the assembly plane);

102 - Final type, color, etc.

103

104 Performance tests of the "Matilda v1.0" prototype (extraction, work, and water use 105 performances) at the different stages of the artisanal extraction of yucca starch

106 A) Reception of the yucca roots: these were subjected to the starch extraction site as quickly as

107 possible (about $24 \mathrm{~h}$ ) after being harvested to prevent physiological damage or microbial 108 deterioration, which might have lowered the quality of the starch;

109 B) Washing and peeling of the roots: at this stage of the process, any possible impurities of the roots

110 after being harvested were eliminated. Yucca was weighed for each experimental block and placed

111 in the washing and peeling machine (machine 1). Several tests were performed to estimate the best

112 wash and hull weight. The optimal amount of water needed to perform this stage in the best way for 
113 the operator was also measured, that is, with the maximum load of water and cassava roots in

114 machine 1 that would allow handling without difficulty and easy operation;

115 C) Grating of the roots: this stage was carried out with a rotary grater (machine 2) with a diameter 116 of $35 \mathrm{~cm}$, an area of $110 \mathrm{~cm}^{2}$, holes of $1.2 \mathrm{~mm}$ in diameter with 2 perforations per $\mathrm{cm}^{2}$, and a density 117 of 594 holes $/ \mathrm{cm}^{2}$. Each load ( $\mathrm{kg}$ of washed and peeled yucca) and the grating time were evaluated 118 to standardize this stage;

119 D) Sieving and starch extraction from yucca root grinding: this process was intended to separate the 120 fiber from the yucca root that would be deposited in the slurry (water + starch). The sieve was 59 $121 \mathrm{~cm}$ wide by $62 \mathrm{~cm}$ long with a depth of $8 \mathrm{~cm}$. Sieving time was a factor to evaluate in our response 122 surface design;

123 E) Starch sedimentation: in this process, the objective was to decant the starch granules suspended 124 in water. The optimum amount of water for sedimentation was also evaluated;

125 F) Starch drying: At this point, the aim was to eliminate the moisture contained in the starch up to 12612 or $10 \%$. This was done in the machine 3 (solar oven). The time of starch rotation and the drying 127 time in the solar furnace were used as factors in our optimization design. The moisture percentage 128 was determined according to COVENIN (1980) and FAO, WHO (1995). Three replicates were 129 taken for each tray or treatment. Finally, in the precision stage, the difference between the results 130 obtained for the two determinations of the same test was calculated and must not be greater than $1310.2 \%$. The yield was established through the percentage relationship between the weight of starch 132 obtained and the weight of washed and peeled yucca used in grating in each treatment or tray 133 (Aristizábal et al., 2007). Finally, the conditioning of starch grinding, sifting, and packaging were 134 completed (Aristizábal et al., 2007). 
136 Optimization of the yucca starch production process, using the technological process built

137 (response surface method - RSM)

138 Once the best peeling and washing conditions of yucca and the optimal use of the water were

139 determined, the extraction process was optimized, with emphasis on sieving and drying in the oven

140 the starch obtained, following the response surface methodology (RSM) (Box \& Wilson, 1951;

141 Montgomery, 1986).

142 The RSM design was a complete factorial $2^{3}$ (three factors and two levels) central composite Box-

143 Wilson factorial design (DCC) blocked (per day), rotatable and orthogonal $(\alpha=1.86)$. Factor 1 was

144 the sieving time with 2 levels plus the zero point $(20,40$ and 60 min; in coded units: $-1,0,+1)$;

145 Factor 2 was the rotation of the material during drying and two levels plus the zero point (2, 3 and

1464 turns, coded units: $-1,0,+1)$. Factor 3 was the drying time and the levels plus the zero point were

147 2, 4 and $6 \mathrm{~h}$ (in coded units: $-1,0,+1)$ (Fig. 1).
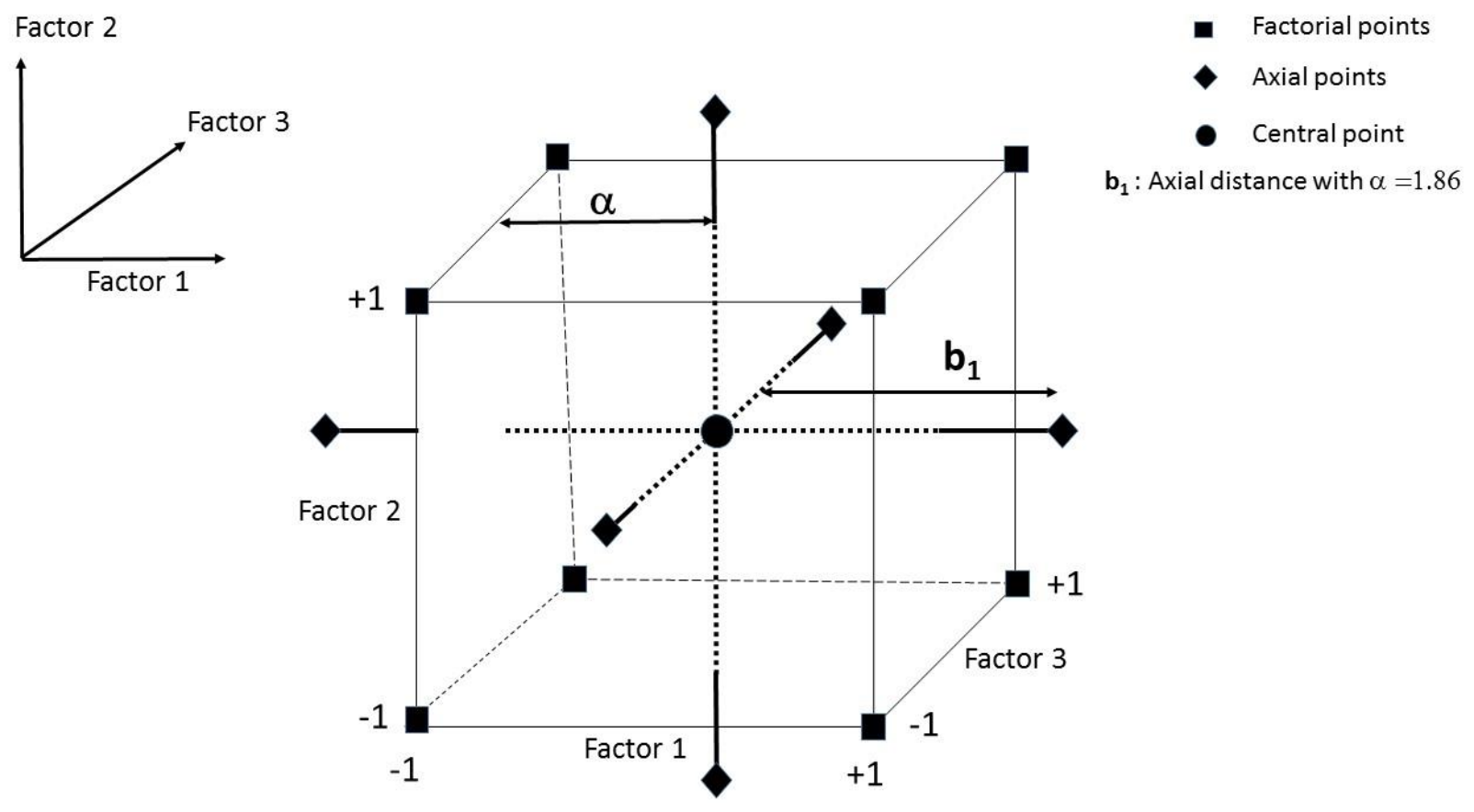

149 FIGURE 1. Graphical model of the DCC factorial design. The image shows the three factors to be 
150 evaluated, eight factorial points, four axial points and the single central point. $b_{1}$ represents the axi 151 al distance for $\alpha=1.86$.

152 The experimental design with the randomized arrangement of the runs, factors, blocks, and the 153 response variables (\% humidity and yield) are shown in Table 1 . The test was performed in three

154 blocks and 42 strokes (treatments) were carried out in total (14 runs per block). This design 155 consisted of six replicates of the central point, eight factorial points with three replicates and six 156 axial points with two replicates each. In this way, the experimental error was efficiently estimated 157 for the design to be sufficiently robust. The estimated regression model of the DCC design was a 158 second-order polynomial (Eq. 1): $Y_{123}=\beta o+\beta_{1} X_{1}+\beta_{2} X_{2}+\beta_{3} X_{3}+\beta_{11} X_{1}^{2}+\beta_{22} X_{2}^{2}+\beta_{33} X_{3}^{2}+\beta_{12} X_{1} X_{2}+\beta_{13} X_{1} X_{3}+\beta_{23} X_{2} X_{3}+\xi$

$161 \quad(1)$

162 where:

$163 \mathrm{Y}_{123}$ is the experimental observation

$164 \mathrm{X}_{1}$ is the sieve time of starch (min.)

$165 \mathrm{X}_{2}$ is the starch rotation time during drying (number of turns).

$166 \mathrm{X}_{3}$ is the drying time of the starch (min.)

$167 \quad \beta$ 's are the factor coefficients

$168 \xi$ is the experimental error 169

170 The $\beta$ coefficients were estimated using the least squares method. The optimization was performed 171 according to the method of the desirability function where the performance conditions are 172 maximized. For the statistical analysis, the Design-Expert v7.15 (Stat-Easy, 2008) software was 173 used under license 2155-6384-4138-EVAL. Each tray in the solar dryer was filled with equal 
174 volume until all the starch obtained in each sieving treatment was used (total of 6 trays per

175 treatment). This way, each yield per tray was multiplied by 6 (Fig. 2).

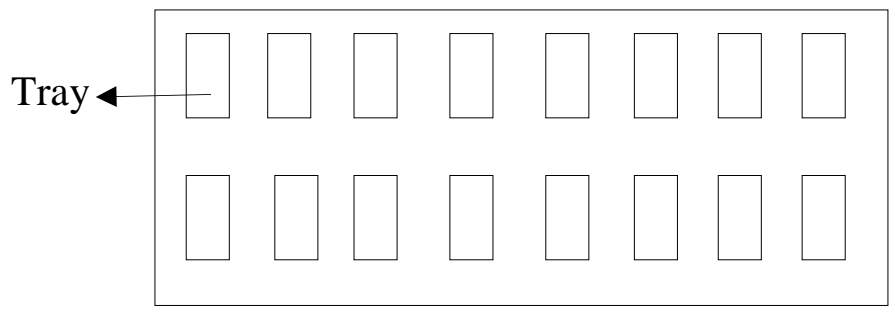

Solar Dyer

178 FIGURE 2. Diagram of the top view of the solar dryer showing the layout of the trays or treatments

179 per block.

\section{Results and discussion}

183 Technical report, description and drawings of the prototype of machines obtained for the 184 extraction of cassava starch (MATILDA v1.0.)

185 After an exhaustive review of the literature and several preliminary tests, a technological process 186 consisting of the MATILDA v1.0 prototype was developed (Fig.3). The process consisted of a series

187 of coupled machines able to extract yucca starch under artisan standards and contemplating the 188 following criteria:

189 - Simplification of the artisanal yucca starch extraction process (Aristizábal et al., 2007), 190 concentrating several stages on one or at least two machines, complying with the standard described 191 in the manual; 
- Manual operation;

193 - Made with low-cost materials;

194 - Showed an optimal management of the water resource;

195 - Showed a good yield of starch production;

- Low maintenance cost.

197

198

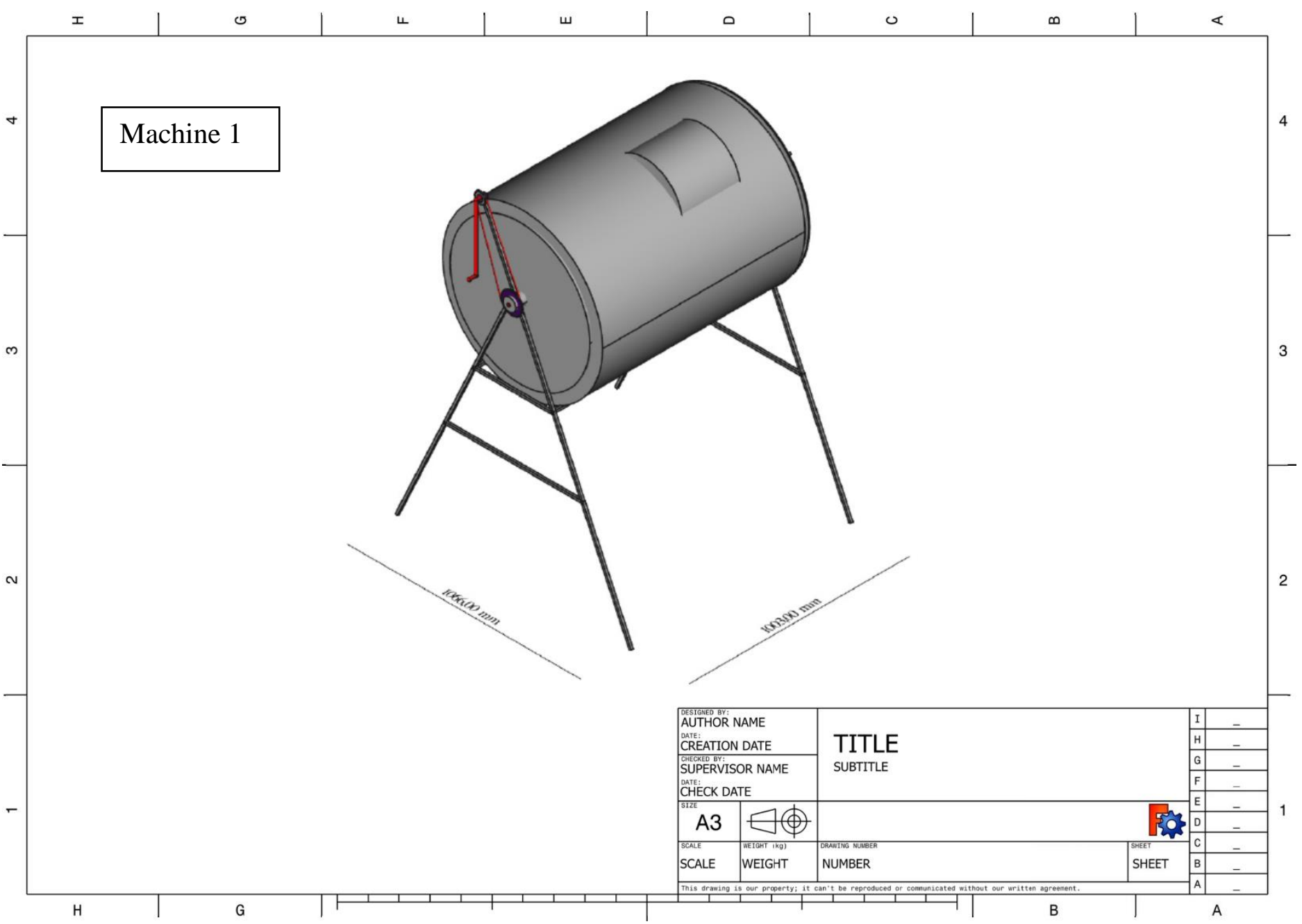




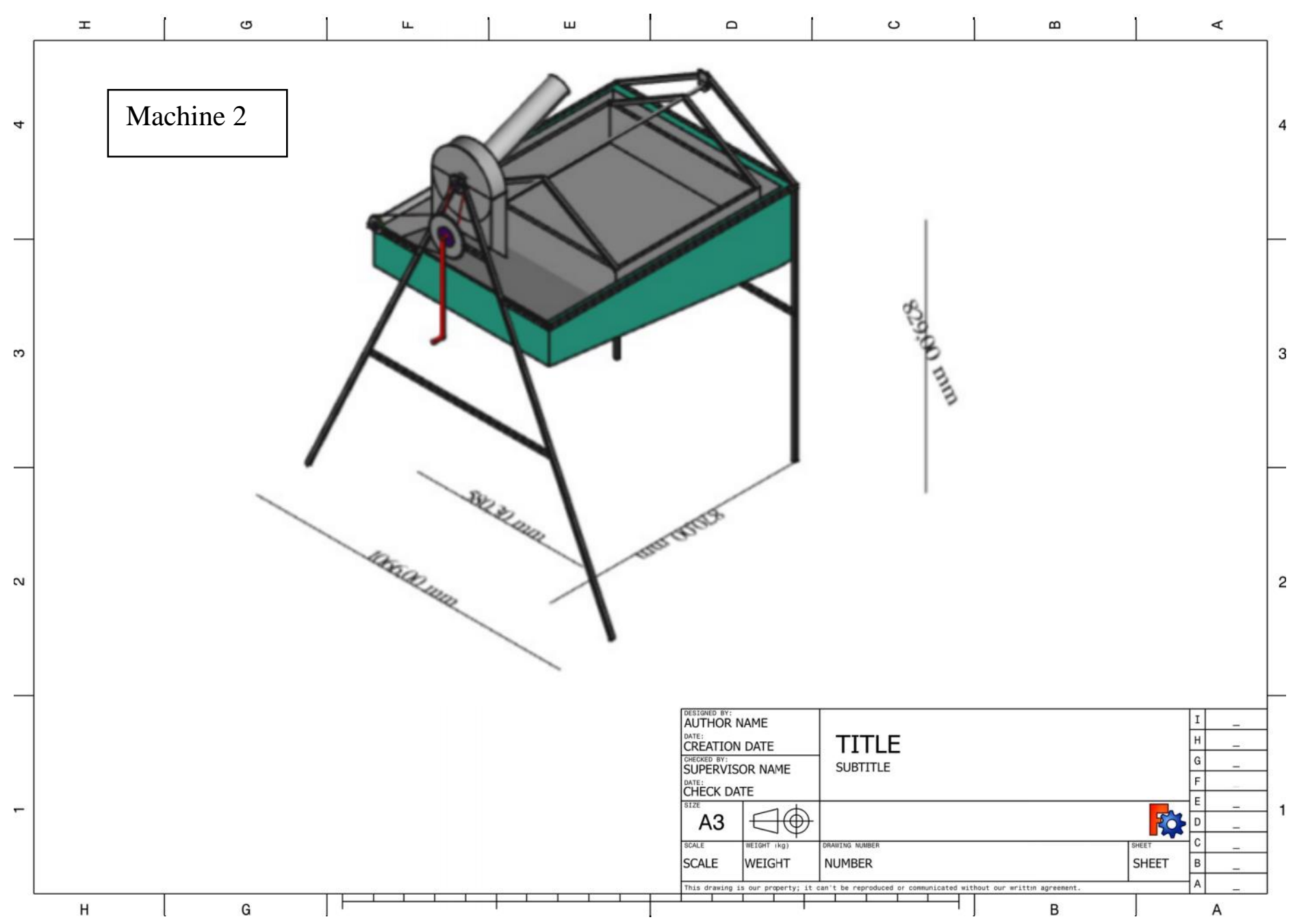

214

215

216

217

218

219 


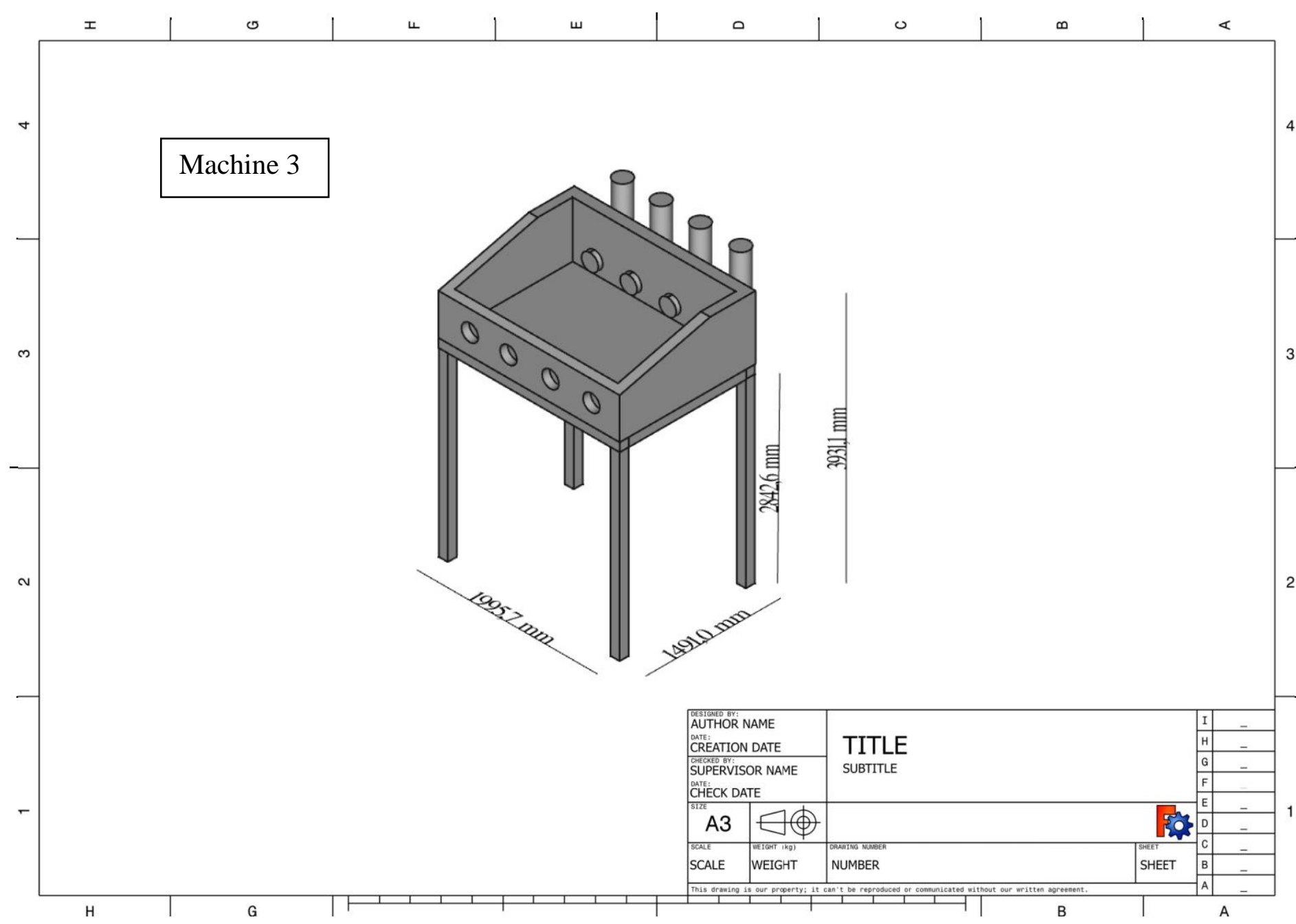

FIGURE 3. Isometric views of the MATILDA v1.0 prototype (the different machines are indicated). It was used FreeCAD v0.15 software (FreeCAD, 2015) 
234 Prototype performance tests in the artisanal extraction of starch and optimization by response

235 surface of the sieving time, starch rotation time during drying, and drying time in the solar

236 furnace

237

238 Table 1 shows the estimated performance for the washing and peeling stages as well as the grating

239 of the yucca. The washing and peeling load were calculated by working time $\left(6-8 \mathrm{hd}^{-1}\right)$ resulting on

240 a work capacity of about $200 \mathrm{~kg}$ of yucca per d and approximately $60 \mathrm{~kg}$ of starch was produced/d

241 (maximum starch yield of 32\%). This finding is above the rallanderias (artisanal starch Colombian

242 producer). The use of water is about $0.31 \mathrm{~kg}^{-1}$ of yucca material. Significantly, this value was less

243 than that of the rallanderias, who report a consumption of water up to $201 / \mathrm{kg}$ of yucca. In respect

244 to the starch yield (32\%), it is located at midpoint between the semi-industrial yield (40-50\%) and

245 conventional artisanal yield (17-20\%) (Aristizábal et al., 2007).

246 In summary, the developed system contemplates an efficient use of water that would benefit peasant

247 communities where this resource is limited. Although the machines are of manual traction, a

248 satisfactory working capacity was obtained that could serve small producers of yucca (productions

249 of $1 / 4$ of ha). These producers represent a major part of Venezuelan and other Latin-American

250 farmers, who do not usually have access to electric energy. We emphasize that, estimated starch

251 production allows for the use of this product as a substitute for food-containing wheat flour. This

252 increases the quality of life of farmers by assuring a better economic income and, at the same time,

253 reducing dependence on imported products.

254

255 TABLE 1. Summary of Matilda's performance for maximum workload. 


\begin{tabular}{cccccc}
\hline MCW/L & MVW & WT/ML & MCW/L & WT/ML & OVW/L \\
Machine 1 & Machine 1 & Machine 1 & Machine 2 & Machine 2 & Machine 257 \\
$(\mathrm{kg})$ & $(\mathrm{l})$ & $(\mathrm{min})$ & $(\mathrm{kg})$ & $(\mathrm{min})$ & (l) 258 \\
\hline 10 & 5 & 10 & 10 & 20 & 30259
\end{tabular}

MCW/L - maximum yucca weight/load to use in the machine; MVW - maximum volume of 261 water/load to be used in machine; WT/ML - working time/maximum load on machine; OVW/L 262 optimal volume of water / load to be used in the machine.

263 Another important technical issue that must be approached in the future is the use of the by-products 264 such as husk, husk bran and residual water for artisanal ethanol production and food formulation.

266 Optimization of the yucca starch production process using the built technological process 267 (response surface method)

268 The moisture reached by the solar dryer was between 20.3 and 30\%, and the starch yield was 269 between 11.3 and 37.1, minimum and maximum, respectively. The $31.8 \%$ starch mean yield was 270 estimated under the optimum operating conditions. The maximum required starch moisture of $12 \%$ 271 could not be obtained due to adverse climatic conditions (Fig. 4). For compute starch yield, required 272 starch moisture was obtained using electrical oven. 


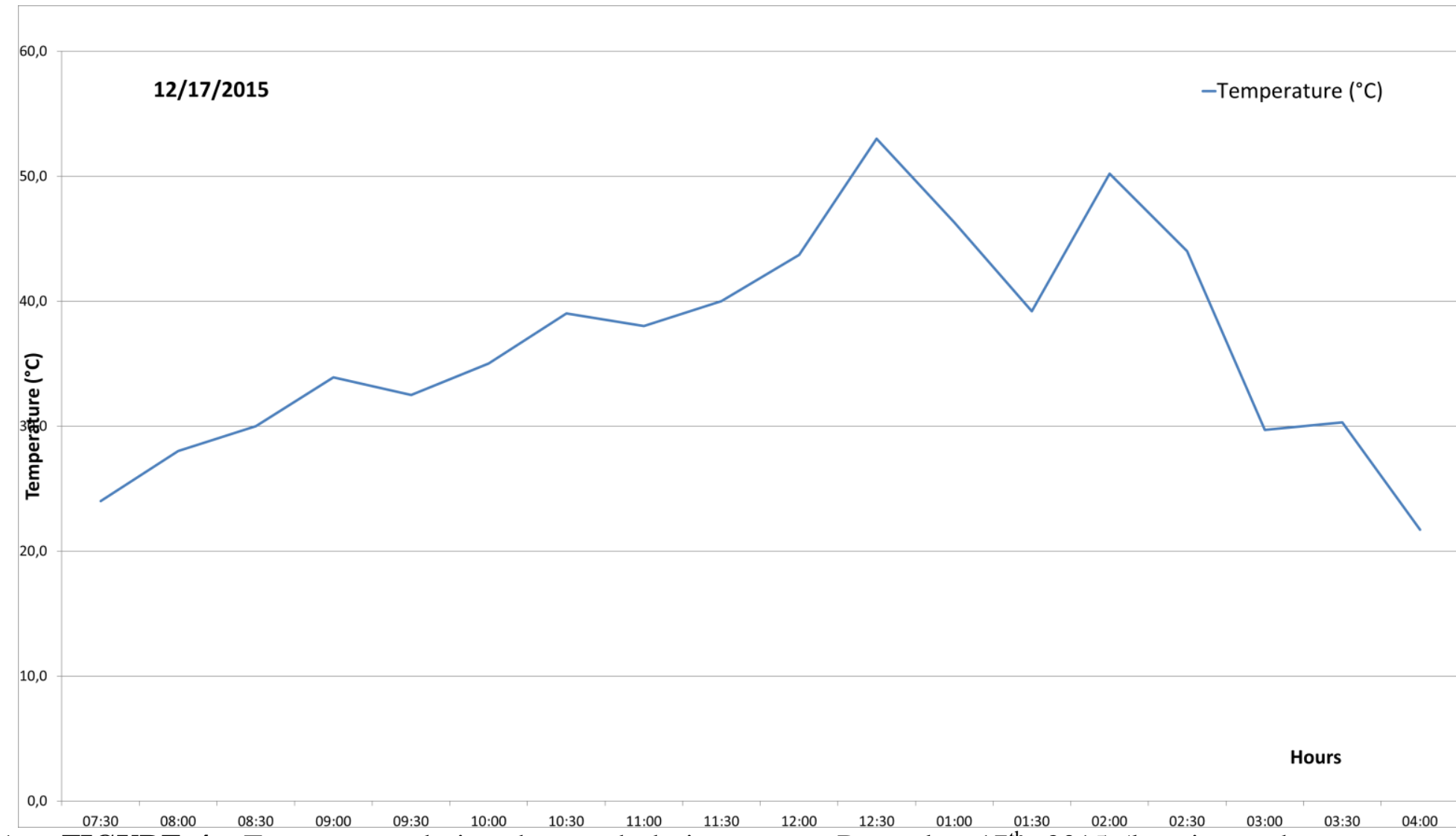

281 FIGURE 4. Temperature during the starch-drying test on December $17^{\text {th }}$, 2015 (location and

282 climatological data).

283

284 For the moisture variable, the model was not significant and the determination coefficients were

285 very low, which suggests this deficiency of the adjusted model should be explored in new 286 experiments. One possible explanation would be that little variation was observed in the response 287 variable (humidity) due to the climatic conditions under which the drying test was performed. For 
288 this reason, we propose to repeat these experiments to evaluate the humidity again ensuring that it

289 is under appropriate atmospheric conditions.

290 In the case of the performance variable, in addition to the linear components, we observed the

291 presence of quadratic terms and interactions type $X_{1} X_{2}^{2} \quad(P<0.0001)$. The cubic term for the 292 screening time factor, although significant, was removed since it was confusing (Fig. 5).

293 Additionally, the model meets the assumptions of normality, constant variance (homoscedasticity),

294 and independence of the residues. Although no satisfactory drying was obtained, the yield variable
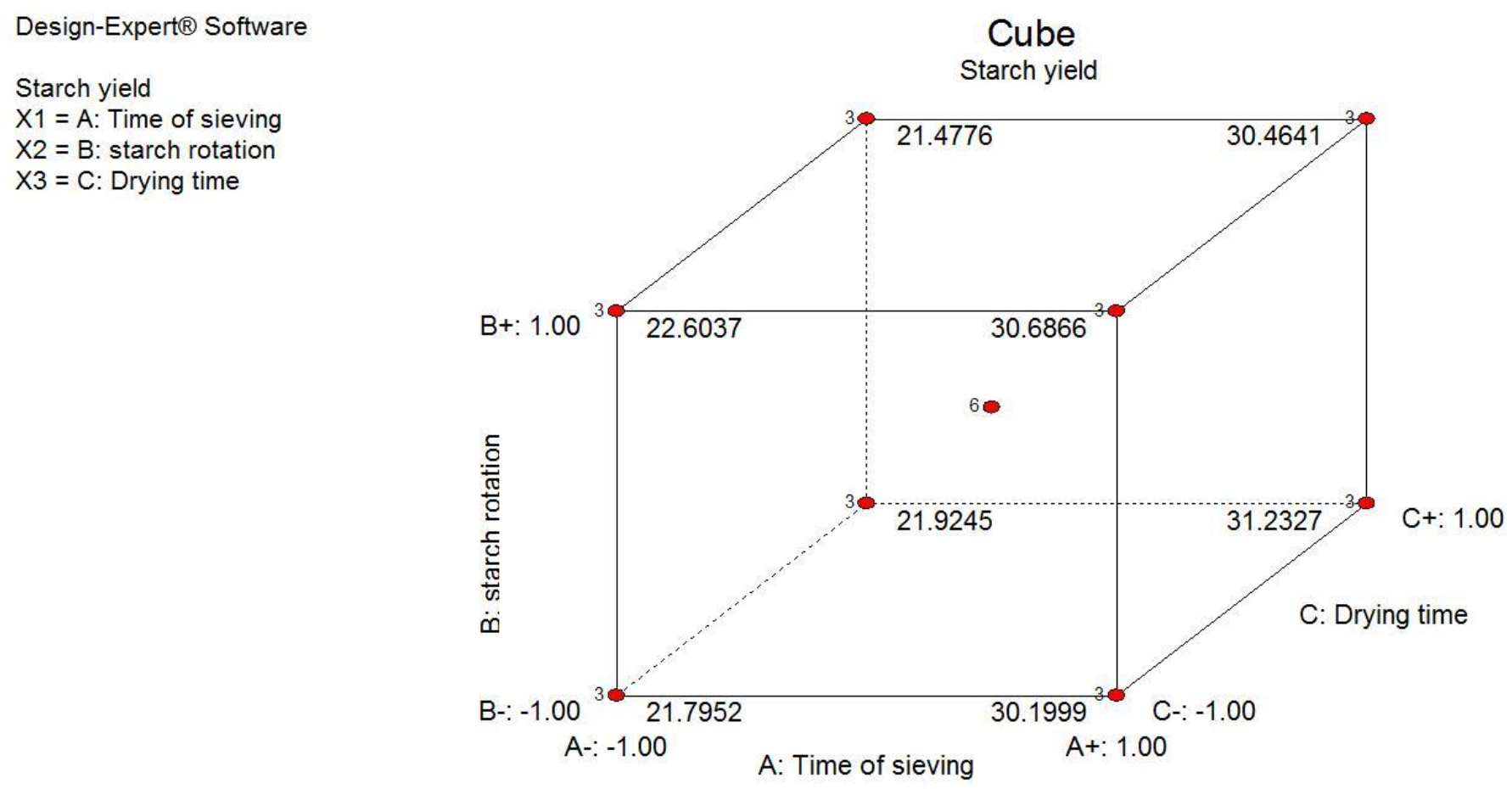

295 was optimized including drying time and starch rotation. This was done because we considered 296 certain interactions and quadratic effects to ensure hierarchical modeling (Eq. 2).

297 FIGURE 5. Graphical model DCC (cube regression reduced and hierarchized model). The image 298 shows the three evaluated factors, the code units, and the starch yield for each tier. The Design299 Expert v7.15 software (Stat-Easy, 2008) was used. 
$Y=31.61+6.44 X_{1}+0.08 X_{2}-0.09 X_{3}-4.06 X_{12}-0.60 X_{2}^{2}-0.59 X_{3}^{2}+0.03 X_{1} X_{2}-3.2 X_{1} X_{2}^{2}$

302

304 The analysis of variance (ANOVA) (Tab. 2) showed that the estimated model for yield is 305 statistically significant $(P<0.0001)$ and the lack of adjustment was not significant with $\alpha=0.01$,

306 suggesting that the model and the order of the polynomial were appropriate. The simple and adjusted 307 coefficients of determination $r^{2}=0.94$ and $r^{2}$ adj $=0.92$, respectively (the difference between the two 308 should not be greater than 0.2) suggest that the model explained the variability present in the data 309 in more than 90\%. The precision value (Adeq. Precision) of 30.4 was sufficient to ensure an 310 adequate model (Tab. 3).

312 TABLE 2. ANOVA for the response variable starch yield.

\begin{tabular}{|l|l|l|l|l|l|l|}
\hline $\begin{array}{l}\text { Source of } \\
\text { variation }\end{array}$ & \multicolumn{1}{|c|}{$\begin{array}{c}\text { Square } \\
\text { Sum }\end{array}$} & $\begin{array}{c}\text { Degree of } \\
\text { freedom }\end{array}$ & $\begin{array}{c}\text { Mean } \\
\text { square } \\
\text { error }\end{array}$ & $\boldsymbol{F}$ & $\boldsymbol{p}$-valor & $\begin{array}{c}\text { Statistical } \\
\text { significance }\end{array}$ \\
\hline Block & 1281.04 & 2 & 640.52 & & & \\
\hline Model & 1370.09 & 8 & 171.26 & 61.14 & $<0.0001$ & $*$ \\
\hline$A$ & 575.54 & 1 & 575.54 & 205.47 & $<0.0001$ & $*$ \\
\hline $\mathrm{B}$ & 0.23 & 1 & 0.23 & 0.081 & 0.7773 & \\
\hline $\mathrm{C}$ & 0.31 & 1 & 0.31 & 0.11 & 0.7403 & \\
\hline $\mathrm{AB}$ & 0.017 & 1 & 0.017 & $5.919 \mathrm{E}-$ & 0.93292 & \\
\hline $\mathrm{A}^{2}$ & 494.31 & 1 & 494.31 & 176.47 & $<0.0001$ & $*$ \\
\hline $\mathrm{B}^{2}$ & 10.64 & 1 & 10.64 & 3.80 & 0.0604 & \\
\hline $\mathrm{C}^{2}$ & 10.61 & 1 & 10.61 & 3.79 & 0.0607 & \\
\hline $\mathrm{AB}^{2}$ & 90.02 & 1 & 90.02 & 32.14 & $<0.0001$ & $*$ \\
\hline
\end{tabular}

*: $p<0.01$. NS: Not significant 


\begin{tabular}{|l|l|l|l|l|l|l|}
\hline $\begin{array}{l}\text { residual } \\
\text { error }\end{array}$ & 86.83 & 31 & 2.80 & & & \\
\hline lack-of-fit & 18.34 & 6 & 3.06 & 1.12 & 0.3814 & $\mathrm{NS}$ \\
\hline pure error & 68.49 & 25 & 2.74 & & & \\
\hline total col & 2737.96 & 41 & & & & \\
\hline
\end{tabular}

314 TABLE 3. Summary of model $F$-value.

\begin{tabular}{|c|c|c|c|c|c|}
\hline Std dev. & Mean & CV.\% & $\mathrm{R}^{2}$ & Adj. $\mathrm{R}^{2}$ & Adeq. precision \\
\hline 1.67 & 26.87 & 6.23 & 09404 & 0.9250 & 30.422 \\
\hline
\end{tabular}

Stad dev.: standard deviation. CV\%: coefficient of variation. $\mathrm{R}^{2}$ : simple coefficient of

316 determination. Adj. $\mathrm{R}^{2}$ : adjusted coefficient of determination. Adeq. precision: adequate precision.

\section{Optimization process}

321 A canonical analysis was performed to estimate the optimal working conditions of machine 2 and

322 machine 3 to obtain the conditions of maximum operating performance.

323 From the model (Eq. 2), the response surfaces (Fig. 4) were plotted for the factors studied and under

324 the specified operating conditions. The non-local maxima (optimal starch yield) were achieved by

325 the gradient ascending method (Box \& Wilson, 1951). Curvature inspection of the response surface,

326 showed sufficient and necessary stability (no saddle points or local maxima), suggesting the

327 existence of these optimum points unequivocally (Fig. 4).

328 The estimated optimal points were obtained: sieving time (45 min); starch removal time (3 turns

329 during the drying period) and drying time (4 h $20 \mathrm{~min}$ ) with a temperature range of $40-60^{\circ} \mathrm{C}$ for the

330 maximum yield confidence interval of 30.24-32.97\% and a prediction interval of 27.98-35.23\%. 


\section{Design-Expert $\circledast$ Software}

Starch yield

- Design points above predicted value

4.1

0 Design points below predicted value
37.0594
11.29
X1 = A: Time of sieving
$\mathrm{X} 2$ = B: Rotation of the starch
Actual Factor
C: Drying time $=0.00$

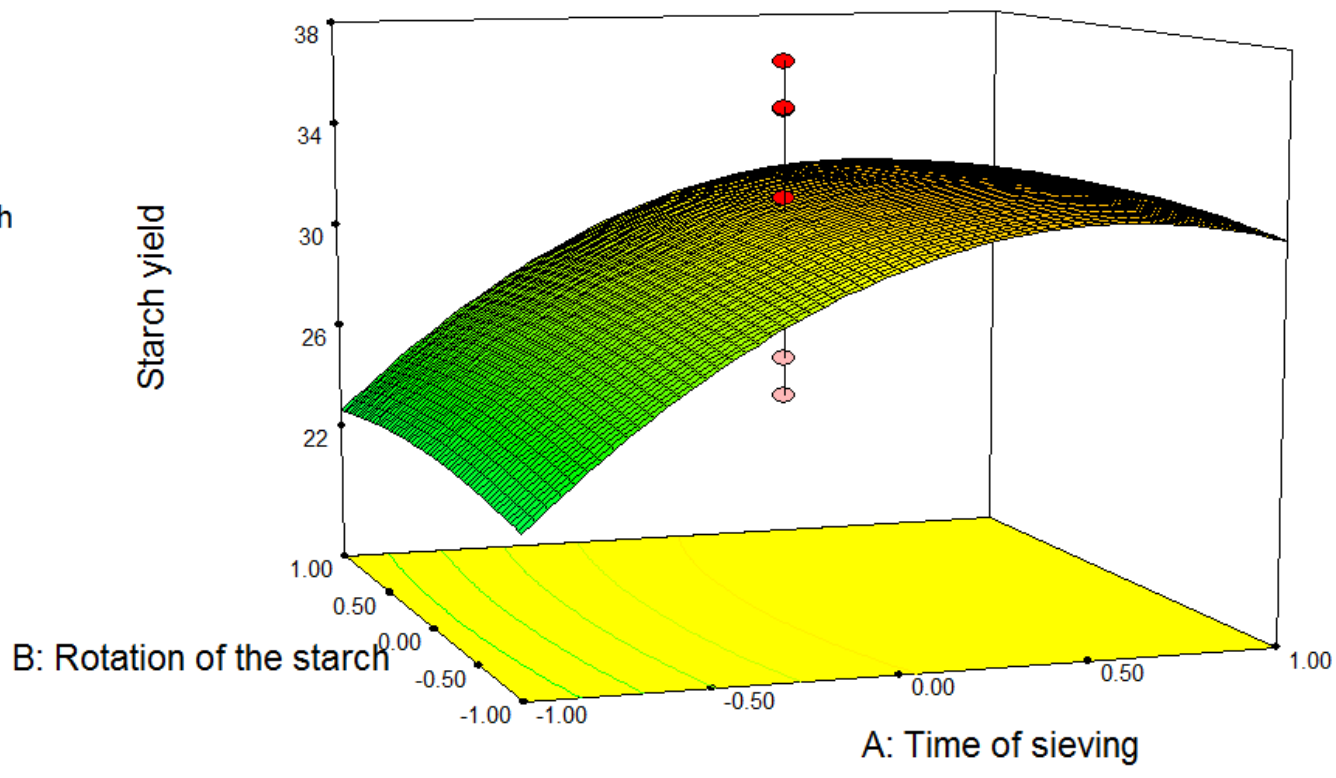

333

334 


\section{Design-Expert® Software}

Starch yield

- Design points above predicted value

Q Design points below predicted value

37.0594

11.29

$\mathrm{X} 1=\mathrm{A}:$ Time of sieving

$\mathrm{X} 2=\mathrm{C}$ : Drying time

Actual Factor

B: Rotation of the starch $=0.00$
흘

C: Drying time

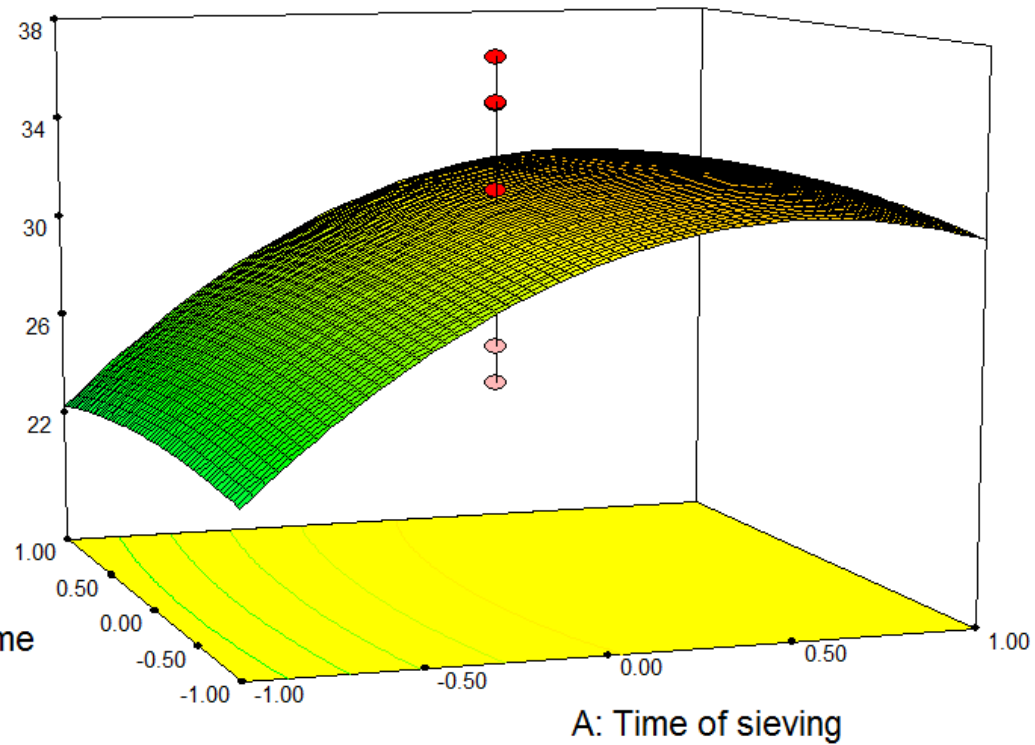


Design-Expert® Software

Starch yield

37.0594

11.29

X1 = B: Rotation of the starch

$\mathrm{X} 2$ = C: Drying time

Actual Factor

A: Time of sieving $=-0.19$

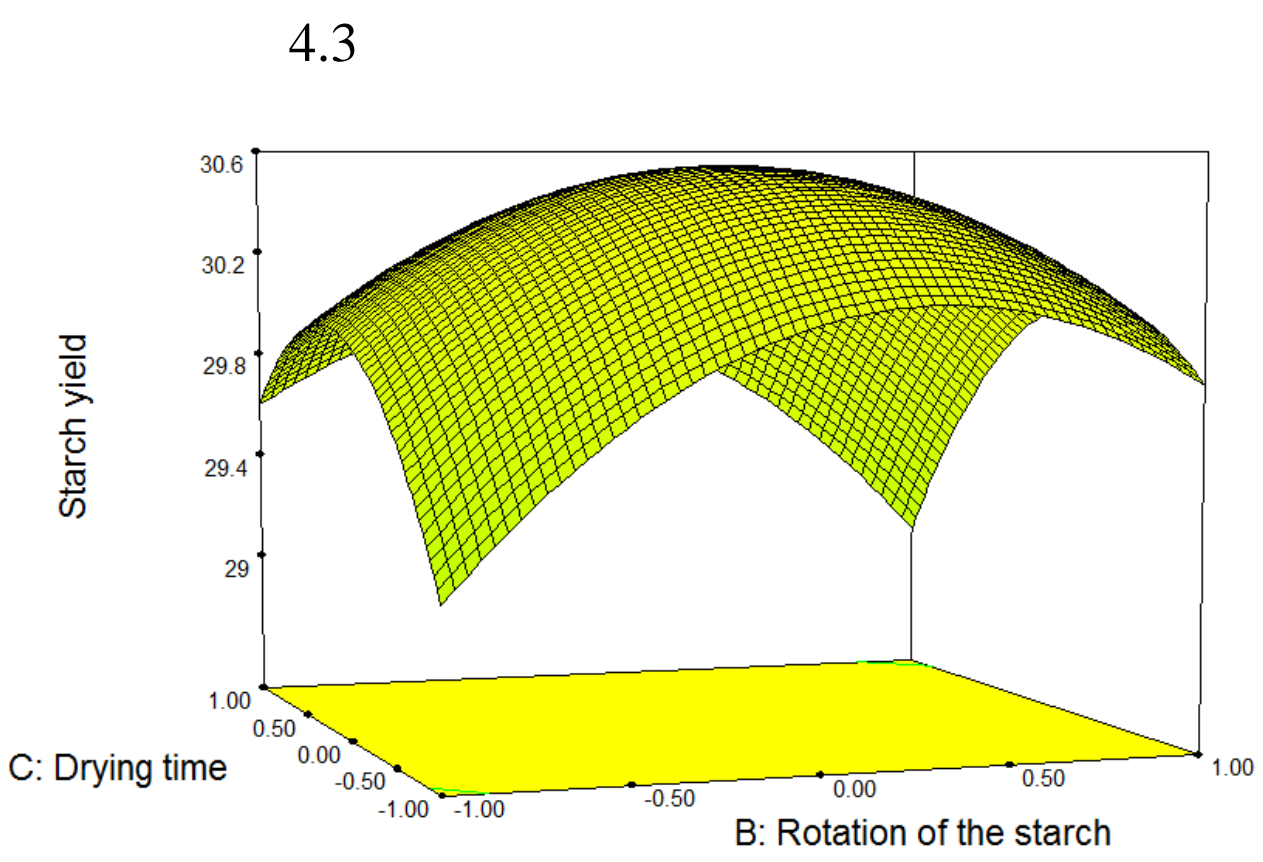

352

353

354 FIGURE 4. Response surface model (contours and 3-D views) of the starch yield (starch yield is 355 displayed in percentage units as explained in the previous sections) as a function of predictor 356 variables (4.1: rotation of the starch vs. time of sieving, 4.2: drying time vs. time of sieving, and 357 4.3: drying time vs. rotation of the starch). Predictor variables are shown dummy units. Also, 358 prediction interval was shown. The software Design Expert v7.15 (Stat-Easy, 2008) was used. 


\section{Conclusions}

363 Three machine prototypes were designed and constructed for yucca root processing with the

364 objective of optimizing FAO grade starch extraction. Through the evaluation of the performance of

365 this process (extraction performance, work performance, water use), it was possible to verify a

366 substantial water saving and the high yield of the final product. This takes into consideration the

367 security this system provides to the operator and the ease of its manipulation, simplifying the 368 process of artisan extraction of the yucca starch.

369 The artisan extraction process (washing/peeling, grating/sieving/sedimentation) of the starch was 370 optimized by the response surface methodology, obtaining a superior performance compared to the 371 reported one to conventional artisanal processes. It is emphasized that during the drying process, 372 which was carried out in the solar furnace, the desired humidity was not obtained due to the climatic 373 conditions of the area. This fact suggests the high dependence of this last stage on environmental 374 factors. This system for starch extraction directly impacts the peasantry, since the developed system 375 would allow obtaining extra economic benefits with the processing of yucca roots that often 376 represent a marginal crop, thus, improving their quality of life.

378 These designs can be modified and adapted to the conditions and needs according to the zone or 379 country and their energy capacities to improve the yucca yields; thus, if there is an access to 380 electricity and facilities to adapt mechanical force through an electrical system, this would reduce 381 the times of starch extraction. It is necessary to emphasize the use of alternative energies such as 382 hydraulic and wind, which are very easy to adapt, depending on the conditions of the area to be 383 used. Regarding the solar furnace, the possibility of adapting forced ventilation is proposed, which 
384 would allow a faster and even starch drying. These machines could be made with more resistant

385 materials such as stainless steel to make them more durable.

387 Acknowledgments

388 The author is deeply grateful for the valuable contribution in the development of this research to 389 Denisse E. Muñoz for drawings and plans. I would also like to thank Richard Ulloa and Jesus 390 Villalobos for their contribution to build the machines and collecting the data, and Raúl Albán for

391 the draft transcription. Special thanks to Tadeo Lara and Carmen Anticona for their important and 392 invaluable suggestions. The author wishes to express his deepest gratitude to Creatividad Ética, as 393 well as Apoidea Soluciones Sustentables organizers of the "Sustainable Design and Innovation 394 Route (DelS), Buenos Aires edition" for awarding the 2nd prize in the category "Product Ideas of 395 Sustainable Design "of 2016 to the" Matilda project "embodied in this paper.

397 Conflict of interest statement

398 The author declares that there is no conflict of interest regarding the publication of this article.

\section{Author's contributions}

401 The author carried out the conceptualization, design (methodology), analysis, interpretation of data 402 and formal analysis of the published findings as well as the writing and revision of this article.

\section{$404 \quad$ Literature cited}

405 Acosta, L. (2005). Practical guide for the systematization of technical cooperation projects and 406 programs. FAO. 
407 Alarcón, F. M., \& Dufour, D. (2012). Cassava sour starch in Colombia. In B. Ospina, \& H. Ceballos

408 (Eds.), Cassava in the third millennium: modern production, processing, use, and marketing 409 systems (pp. 496-525). Centro Internacional de Agricultura Tropical, Consorcio Latinoamericano 410 y del caribe de Apoyo a la investigación y desarrollo de la Yuca, Technical Centre for Agricultural 411 and Rural Cooperation.

412 Álvarez, E., Belloti, A., Calvert, L., Arias, B., Cadavid, L. F., Pineda, B., Llano, G., \& Cuervo, M. 413 (2002). Guía práctica para el manejo de las enfermedades, las plagas y las deficiencias 414 nutricionales de la yuca. Centro Internacional de Agricultura Tropical, (CIAT) Consorcio 415 Latinoamericano y del caribe de Apoyo a la investigación y desarrollo de la Yuca.

416 Aristizábal, J., \& Sánchez, T. (2007). Guía técnica para producción y análisis de almidón de yuca. 417 FAO.

418 Bello-Pérez, L. A., González-Soto, R. A., Sánchez-Rivero, M. M., Gutiérrez-Meraz, F., \& Vargas419 Torres, A. (2006). Extrusión de almidones de fuentes no convencionales para la producción de 420 almidón resistente. Agrociencia, 40(4), 441-448.

421 Box, G. E. P., \& Wilson, K. B. (1951). On the experimental attainment of optimum conditions. 422 Journal of the Royal Statistical Society, 13(1), 1-45.

423 Cartay, R. (2004). Difusión y comercio de la yuca (Manihot esculenta) en Venezuela y en el mundo. 424 Agroalimentaria, 9(18), 13-22.

425 COVENIN. (1980). Norma Venezolana COVENIN 1513-80. Productos de cereales y leguminosas: 426 determinación de humedad. Comisión Venezolana de Normas Industriales. 
427 Oliveira, O. S., Brito, V. H. S., \& Cereda, M. P. (2019). Establishing a standard for handmade

428 Brazilian cassava flour from Baixada Cuiabana (Mato Grosso, Brazil) to support its processing and 429 sale. Food Science and Technology, 39(3), 559-566. https://doi.org/10.1590/fst.30117

430 Domínguez, C., Ceballos, L. F., \& Fuentes, C. (1983). Morfología de la planta de yuca. In C. E. 431 Domínguez (Ed.), Yuca: Investigación, producción y utilización (pp. 24-49). Programa de las 432 Naciones Unidas para el Desarrollo, Centro Internacional de Agricultura Tropical.

433 Ehinmowo, O. O., \& Ojo, S. O. (2014). Analysis of technical efficiency of cassava processing 434 methods among small scale processors in south-west, Nigeria. American Journal of Rural 435 Development, 2(2), 20-23. https://doi.org/10.12691/ajrd-2-2-1

436 FAO \& WHO. (1995). Codex standard for edible cassava flour Codex Stan 176-1989. In Codex 437 Alimentarius Volume 7 - 1995. Food and Agriculture Organization of the United Nations, World 438 Health Organization.

439 FreeCAD. (2015). FreeCAD v0.15 software. https://www.freecadweb.org/

440 Maliro, M. F. A., \& Lameck, G. (2004). Potential of cassava flour as a gelling agent in media for 441 plant tissue culture. African Journal of Biotechnology, 3(4), 244-247.

442 Montgomery, D. C. (1986). Design and analysis of experiments (2nd ed.). Wiley.

443 Ngnassi, D. A. B., Doka, Y. S., \& Nzie, W. (2019). Design of a cassava processing unit in starch. 444 International Journal of Innovations in Engineering Research and Technology, 6(3), 39-48.

445 Parmar, A., Sturm, B., \& Hensel, O. (2017). Crops that feed the world: production and improvement 446 of cassava for food, feed, and industrial uses. Food Security, 9, 907-927. 447 https://doi.org/10.1007/s12571-017-0717-8 
448 Romay, G., Matheus, J., Gerstl, A., Rueda, R., \& Santana, M. A. (2006). Almidón modificado de 449 yuca como sustituto económico del agente solidificante para medios de cultivo de tejidos vegetales. $450 \quad$ Interciencia, 31(9), 686-699.

451 Saranraj, P., Behera, S. S., \& Ray, R. C. (2019). Traditional foods from tropical root and tuber 452 crops: innovations and challenges. In C. M. Galanakis (Ed.). Innovations in traditional foods (pp. 453 159-191). Woodhead Publishing.

454 Shittu, T. A., Alimi, B. A., Wahab, B., Sanni, L. O., \& Abass, A. B. (2016). Cassava flour and 455 starch: processing technology and utilization. In H. K. Sharma, N. Y. Njintang, R. S. Singhal, \& P. 456 Kaushal (Eds.), Tropical roots and tubers: production, processing and technology (pp. 415-450).

457 John Wiley \& Sons, Ltd. https://doi.org/10.1002/9781118992739.ch10a

458 Stat-Ease. (2008). Design-Expert ${ }^{\circledR}$. http://www.statease.com

459 Young, T. L. (2007). The handbook of project management: a practical guide to effective policies 460 and procedures (2nd ed.). Kogan Page.

461 Zambrano, L., \& Sosa, S. (2018). Evolución del consumo de alimentos en Venezuela (1998-2017).

462 Instituto de Investigaciones Económicas y Sociales, Universidad Católica Andrés Bello.

463 Zhu, F., \& Xie, Q. (2018). Structure and physicochemical properties of starch. In Z. Sui, \& X. Kong 464 (Eds.), Physical modifications of starch (pp. 1-14). Springer. https://doi.org/10.1007/978-981-13465 0725-6_1 